\title{
Implementing E-Government Using Web 2.0 at Ministry Of Education And Culture
}

\author{
$1^{\mathrm{st}}$ Rona Uly \\ Faculty of Social Science and Politics \\ Universitas of Indonesia \\ Depok, Indonesia \\ ully.ng1@gmail.com
}

\author{
$2^{\text {nd }}$ Irwansyah \\ Faculty of Social Science and Politics \\ Universitas of Indonesia \\ Depok, Indonesia \\ dr.irwansyah.ma@gmail.com
}

\begin{abstract}
The background of this research comprises; (1) demands to improve public services in the digital era are increasing, (2) the government launches digital services as an adjustment to the behavior of modern people who always rely on the internet in their daily lives, (3) easy access to the government through technology was launched in various sectors so that two-way communication was established between the government and the public to participate in government activities. This statement of the problem in this research relies on "how information and complaints online services in providing feedback to the Ministry of Education and Culture on issues around the users", and "how the interaction between government and users". The research method used in this research is a qualitative approach by conducting interviews with staff of the Integrated Service Unit (Unit Layanan Terpadu) Ministry of Education and Culture, and also a literature study to test ULT (Unit Layanan Terpadu) online information services based on existing concepts. This study found that information services carried out by the ULT Ministry of Education and Culture Website need to be more managed, integrating data from each unit, and provide a feature on the web to discuss or socialize with visitors.
\end{abstract}

Keywords-E-government, web 2.0, Helpdesk Ticketing System, Public service

\section{INTRODUCTION}

The increasing number of internet users has caused the government to issue policies about e-government utilization. The public can easily access information related to the public interest, create control, and interact with the government through the internet. Technology can generate fast, easy, and direct access to the government. Participation has become one of the essential things to enhance the quality of public services in a better direction. The quality of public service can be transformed from conventional to modern through the egovernment system.

E-Government has become a public organization with a new form that supports and redefines existing and new information, communication, and interactions related to transactions with stakeholders (e.g.,citizens and businesses) through ICT, especially through the Internet and Web technology, with the aim to ᄀaimprove government performance and processes [1].

Penetration of internet usage in 2018, according to the Association of Internet Service Providers in Indonesia, is about 171.17 million of the total Indonesian population of 264,16 million people. Internet usage in 2018 based on percentage is around $64,8 \%$ of the Indonesian people already using the internet, where growth is always rising every year. The survey results in 2018 also explained that communication and social media are the main reason people use the internet. This is the reason why government activities in Indonesia are appropriate for moving in the digital realm.

The Ministry of Education and Culture (MoEC), as a public organization must provide public service. The Presidential Decree No. 97 of 2014 concerning the Implementation of One-Stop Integrated Services makes public service in each unit within the MoEC are managed under the Communication department. It $\neg$ is called the Integrated Services Unit (Unit Layanan Terpadu)

There are two types of services provided by ULT that are direct or face-to-face and indirect services. The indirect service such as SMS, telephone, email, letter, fax, and web. Improving public service through personal interaction with people using digital media is essential because many information and complaint services contains personal data. This is the reason why web-based information and complaints services are launched via the www.ult.kemdikbud.go.id, which is called the ULT website. The ULT website has the main features of information services, complaints, and suggestions.

The latest service is online consultation, where the services provided are direct and two-way communication. Another new feature is the online queuing service where people who want to visit ULT MoEC may arrange an appointment using the online queuing feature on the ULT Website, and they will be scheduled to have a consultation after 13.00 WIB or 1 PM. The arrangement are made so visitors who are generally teachers may arrange their teaching schedules and visit ULT without leaving their class. The ULT Website comes as a demand to create a modern, fast, easy and transparency in government. The website was created because of rapid technological developments and can be adapted to the situation of the Indonesian people both geographically and economically.

\section{A. E-Government}

ICTs are the primary key in the modernization of the government[2]. E-government has become an influential agenda for every government in the internet era. The definition of e-government is the use of ICTs in the public sector, which aims to improve access and delivery of public services from citizens, businesses, and communities[3]. E- 
government can improve productivity, provide more significant opportunities for citizens to participate in activities and decisions made by a democratic government, and build trust between government and citizens [4]. The World Bank in 2002 defines e-government as a government-operated information system and communication technology (ICT) that changed relations with citizens, the private sector and/or other government institutions to promote citizens' empowerment, improve service delivery, strengthen accountability, increase transparency, or increase government efficiency[5]. Egovernment can increase productivity, provide more significant opportunities for citizens to participate in activities and decisions made by a democratic government, and build trust between government and citizens [6].

The stages in the evolution of e-government consist of three parts [7], which describe the patterns of interaction between digital governments and the public. The first phase of e-government is to focus on "digital presence" with the website being a passive provider of simple information, where this stage is called the digitalization of government information. The second phase provides simple web-based interaction from the government with citizens, businesspeople, and other government agencies through email contacts and interactive forms that can dynamically and provide the information needed. The third stage of this evolution is the availability of online transaction services such as license renewals, application permits, and tax payments. The next stage is when the government promotes joint government to change the way they operate, in terms of a smooth flow of information and collaborative decision making.

In these three stages, e-government can be seen as a process of modernizing the public sector from paper-based tasks to moving towards digital. These stages are based on the "information delivery model" and "the public administration process automation model," which results in fast and convenient access to information services and other government services, and achieves more efficient government automation services within and across government agencies. Information in this stage flows in one direction, from the government to the public, with limited feedback from citizens. This type of e-government is called e-government based on Web 1.0 or e-Government 1.0.

The last stage has not yet been fully reached, because the transformation of government requires a meaningful dialogue between the government and the community and dialogue between the citizens themselves. The information must flow not only from the government to citizens but also from citizens to the government and fellow citizens. Citizens' voices must be heard and reflected to change existing government policies. To achieve this kind of transformation, there needs to be an expansion of technological support for citizen participation. Also, the government needs to ensure that it gets information freely and makes that information publicly available for discussion and socialized participation. This dialogue will later promote the collaborative decision-making process by including the community at the beginning of new government policy. This stage introduces the concept of "open government," called "Government 2.0". It requires the conditions, functions, and technology that make it possible to lead to a transformative and participatory e-government model [8].
The development of the web occurs rapidly but does not mean that every organization or agency must directly adapt the latest web technology in the delivery of information and public services. The government may adopt web technology to fulfill the public needs to communicate with the government. Submission of information or policies that are massive should use web technology web 1.0 (read only). Submitting information that requires interaction, must use web 2.0 technology.

\section{Web 2.0}

The term web 2.0 was formally defined in 2004 by Dale Dougherty, vice president of O'Reilly Media, in a conference brainstorm session between O'Reilly and MediaLive International. Web 2.0 is a business revolution in the computer industry caused by the move to the internet as a platform, and efforts to understand the rules for success on that new platform. Web 2.0 is also known as the web of wisdom, human-centric web, participatory web, and web of read-write where the web can be two-way [9]. Web 2.0 is a web as a platform where users can leave many of the controls they have used on web 1.0. Web 2.0 users have more interaction but less control.

One of the amazing features of web 2.0 is to support collaboration and to help collect collective intelligence. Web 2.0's main technologies and services include blogs, Really Simple Syndication (RSS), wikis, mashups, tags, peopleonomy, and tag clouds [9]. The main benefit offered by Web 2.0 for public sector entities is transparency and citizen participation. Web 2.0 has supported the emergence of content created by citizens who can enrich sociopolitical debates and can increase the diversity of opinion, information flow, and freedom of expression. These tools can be used to engage citizens, exchange opinions, provoke debates and share information about social and political issues (OECD, 2007).

Web 2.0 tools and practices can help improve policymaking and service delivery by enriching government interaction with external stakeholders and improving internal knowledge management [10]

The impact of Web 2.0 on the public sector can be seen in four areas:

- Public sector transparency: by using syndicated content and social media platforms to bring public agendas and government activities to be closer to citizens and provide news and information on platforms that are preferred by citizens (no longer need to go to entity websites public to get this information). The core application of Web 2.0 tools and social media for local entities, and can identify the concept of transparency. The government faces unprecedented openness, which is further encouraged through the mobilization of electronic roots using social technology [8]. Noveck shows how adequate information and availability are vital in this democratization scenario. According to Noveck, making useful information available to the general public for governance better is more important than the attention paid to in the past for so-called "experts" [11]

- Improved policymaking is a new form of participation, and will be activated by the use of ICTs, which increase social awareness and citizen involvement. 
The evolution and popularity of social media has provided new techniques for online community involvement and additional avenues for consultation and interaction with citizens and communities in ways that can facilitate dialogue, creativity, collaboration, and participation. All these citizen-to-citizen and citizen-to-government dialogues can have many positive effects[12]

- Public service improvement is a more innovative mechanism in terms of service delivery. As Osimo points out, there are applications of these tools so that the public sector can improve the provision of public services in the same way that companies share product design tasks with potential customers. [2]

- Improving knowledge management and collaboration across institutions, using certain groups in the context of this platform to change relations [13]

\section{METHODOLOGY}

The research used a qualitative approach by describing the problem based on the concept of E-Government and Web 2.0. The analysis is using support from data collected through (a) description of the features contained in the ULT website; (b) ticketing Helpdesk Descriptions adopted by the ULT website; (c) interview with the coordinator of direct and indirect services in ULT and the ULT website; (e) interview with one of ULT website administrator.

\section{RESULT}

\section{A. Web-based Ticketing System Helpdesk}

Online information and complaint handling have been conducted by the Ministry of Education and Culture, which is managed by the Information and Public Relations Center since 2013 through the osTicket (Open Source Ticket) application. In 2015 after the formation of the One-Stop Integrated Service at the Ministry of Education and Culture under the name Integrated Services Unit, online information and complaint handlings were also launched. The ULT website aims to provide even-handed to all stakeholders in Indonesia. People who want to ask about Education and Culture may directly ask online. They should not have to come to the local government as an extension of the Ministry of Education and Culture nor spend money and time visiting the head office in Jakarta.

The ULT website adopts the helpdesk ticketing system used in previous information services through the osticketing.com application. The concept of helpdesk ticketing is taken based on the definition of the idea of helpdesk and ticketing. Helpdesk can be a single point of contact if there are users who need help and want to communicate with the support team in the organization [14]. Helpdesk as a complimentary service can serve to help solve the issue or problem of the user $\neg[15]$.

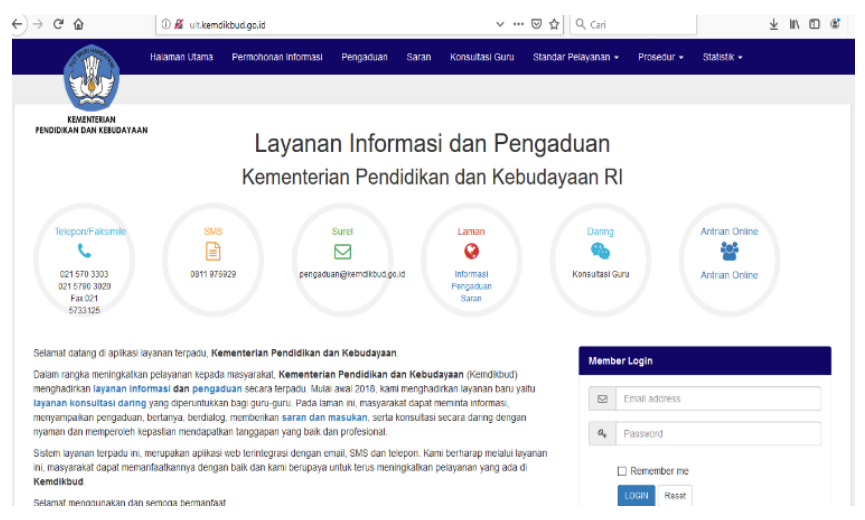

Fig. 1. ULT Website

Ticketing is a ticket (trouble) to detect an issue. Ticketing system adapts the paper reporting system. Ticketing systems that exist today are generally web-based integrated into Customer Relationship Management (CRM) such as call centers [16] Based on the above definition, ticketing helpdesk.

Users who wish to submit inquires about information or complaints to the Ministry of Education and Culture can access the ult.kemdikbud.go.id webpage, then select the suggestions, information, and complaints page. The user will then fill out forms containing personal data, select categories, subcategories, professions, locations, and submit the problems in detail

The stages in e-government consist of three parts: the web phase of information providers, provide interaction, and the online transaction service. The ULT website is in the stage of provide interaction because it takes the form of information and complaint services. The first stage, which is a web of information, is carried out by the website of the Ministry of Education and Culture on the webpage www.kemdikbud.go.id. Phase 3, online transaction providers such as school building permits, electronic procurement, the issuance of decree allowances, still handled in each work unit. It is because there is so much data throughout Indonesia and requires a server with a large capacity.

Users who have sent tickets to inquire about information, express aspirations, or submit complaints will receive an answer from the ULT Portal official in their e-mail in the form of a link to confirm. Users who have confirmed will receive a response in their email in the form of a username and password to log on the page www.ult.kemdikbud.go.id. The user then logs in and can see the first ticket, whether it has been replied or not. A replied ticket can be resumed if they still want to continue the discussion with the same problem or the user can choose the close menu so that the status of the ticket is considered complete. Users who want to ask about other issues can make a ticket by selecting a list that suits their needs.

Another feature that is an innovation is the live chat or online consultation feature. This service wants to present a virtual service for visitors who are located far away or who did not have the chance to come to ULT given that most users are teachers who have to teach from morning until late afternoon. Another feature is the online queue, which is for ULT visitors who want to come directly to ULT and perform services face-to-face so they can take the queue number first 
and will get consultation after 13.00 WIB. Visitors may visit ULT by arranging the schedule and they don't have to queue from the morning.

The tickets per day can reach around 30-50. The amount will reach 60-100 tickets per day at specific periods, such as the disbursement of teacher allowances. The teachers will ask the validity of their data in Dapodik and whether their benefits will be disbursed soon. July - August is also a time when web traffic is heavy, which coincides with the schedule for New Student Admissions (PPDB). The number of tickets can reach 100 where people ask about the newest policies. For example, the procedures related to students' admission in public schools, requirements for registering schools, the admission system related to regional autonomy, and others

\section{B. ULT Website as E-Government}

The ULT website is a medium to bring people closer to the decision-maker. The stages in e-government are divided into 3 parts, namely: the web phase of information providers, providing interaction, and the online transaction service stage. The ULT Website is in the stage of giving two-way communication because it takes the form of information and complaint services. The system can produce a report on the critical issue submitted by users. The first stage is as a web of information providers carried out by the website of the Ministry of Education and Culture on the page www.kemdikbud.go.id, which is only one-way, namely the government to the community. Phase 3, namely online transaction providers such as school building permits, electronic procurement, the issuance of Decree Allowances and others are still done in each work unit, this is because there is so much data throughout Indonesia and requires a server with a large capacity.

Through the ULT website, two-way communication or dialogue occurs from government to citizens and citizens to the government. Sandoval said that this dialogue would later promote the collaborative decision-making process by including the community at the beginning of new government policy. The concept of "open government," called "Government 2.0," is introduced and requires the conditions, functions, and technologies that make it possible to lead to a transformative and participatory e-government model.[8]. The ticketing Helpdesk system in the ULT Portal has a feature for data retrieval which makes it possible to find out what issues are occurring around Education and Culture. Every day administrators will monitor any topics that are trending and report to the management. Data withdrawal schedule every two weeks. Reports with detailed display per category to see trends that occur and to provide results to leaders who have responsibility for decision making and policymakers. Specific cases such as the rise of incidents of bullying in schools or crime in schools will be reported directly to the leaders when events occurred as consideration for the Minister to state the press or the public.

Fang said that e-government could provide more significant opportunities for citizens to participate in activities and decisions democratically. One of the cases involving citizen participation through the ULT Website was complaints from teachers about the process of making Identity Number (NUPTK) in the Ministry of Education and Culture, which involve local government intervention as a result of regional autonomy. The teacher's complaint was not widely reported in the media domain. Still, the results of the data withdrawal on the ULT Website showed that it was problematic so that the leaders felt the need to change the policy as a result. The ministry moved the verification process of making identity number by involving the Educational Quality Assurance Agency (LPMP), which is directly under the Ministry of Education and Culture in each region instead of crossing other agency.

\section{ULT Website and Web 2.0}

Web 2.0 is a web of two-way interactions. The ULT website is a web of information and complaints services where communication occurs between the government and the public. Web 2.0 is known as the wisdom web, human-centric web, participatory web and read-write web [9]. Citizen participation in asking for information and complaints produces a report that can provide input on programs or policies that are not yet understood by the community so that more intensive socialization is needed through the Ministry of Education and Culture or mass media.

The ULT website feature offers interpersonal communication to users because this service is specialized in solving the user's own problems. The information submitted contains personal data such as bank account number of the teacher's allowance, whether teachers allowance decree has been published, the nominal amount of the disbursed allowance, identity number approval process, and others. This type of data cannot be published because someone will misuse this personal information. Each unit has also launched digital applications such as "Info GTK" for teachers, specific websites for checking the National Student Registration Number, etc. However people still ask those particular issues in ULT website because they do not understand how to use those applications.

Features that display dialogue, collaboration of various parties have not been adopted by the ULT portal. The channel for dialogue with the public is carried out on Kemdikbud's social media through Facebook, Instagram, Twitter, Youtube.

The results of data collection that can be reported to the leaders as material for decision making are in several categories. Following are the results of the report in 2018.

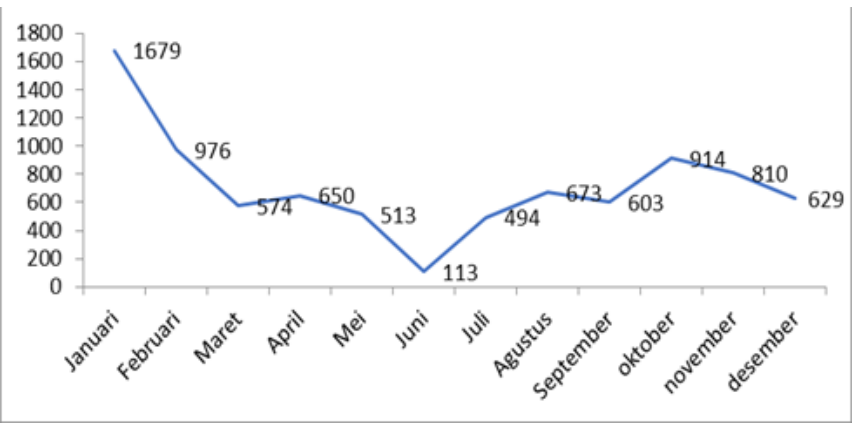

Fig. 2. Report Total Tickets in Year 2018

The graph shows that the number of tickets tends to be high in January, February then decreases and rises again in May then falls back and goes up in November 2018. 

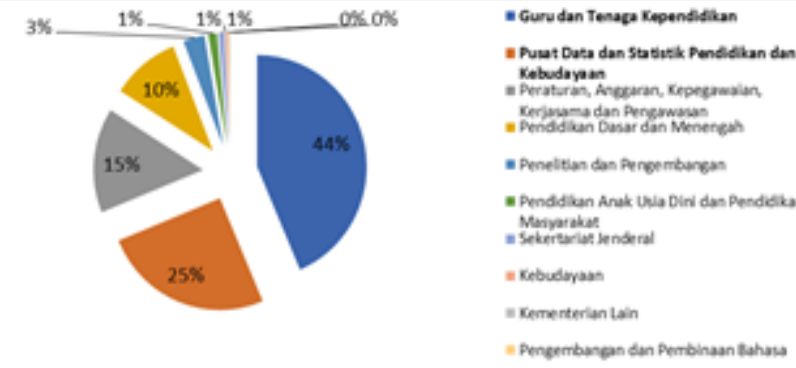

Fig. 3. Report Total Ticket Based on Unit/Category

The Pie Chart above shows which unit the user most frequently asked. Most complaints are directed to a unit that handles teacher's allowance. Leaders who see this will analyze what problems are most commonly asked by users and in what month this unit gets more complaints. The next highlighted section is the Statistical Data Center, which receives the most complaints in sequence number 2 after Teachers and Education Personnel Unit. Leaders will review the most frequently questioned issues and period time that users complain.

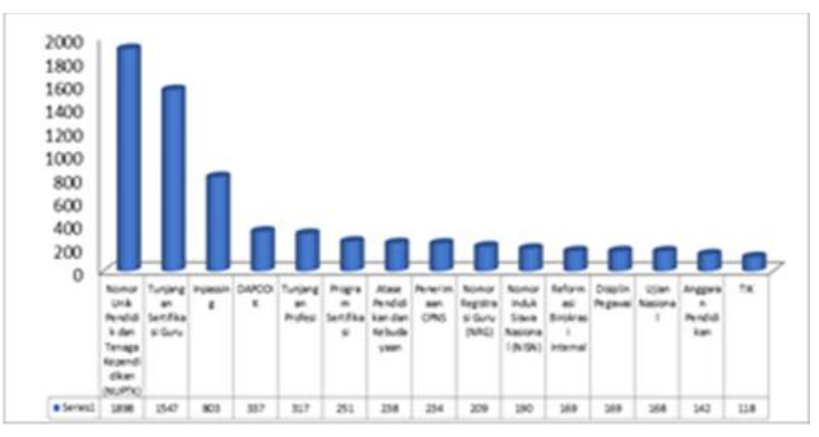

Fig. 4. Report Total ticket based on Profession

The graph above shows what issues are most frequently asked. The data above explain the most problem is about the teacher's identity number. The leaders will review what specific matter caused in this issue arose. In 2018, ULT website visitors had many problems regarding the issuance of teachers' identity numbers. The leaders will then re-record what makes the issuance process constrained, and in what part the process is experiencing obstacles. Community participation in voicing opinions, asking for information and complaints can provide reports to the government and the government can immediately make decisions to change policies to address the problem.

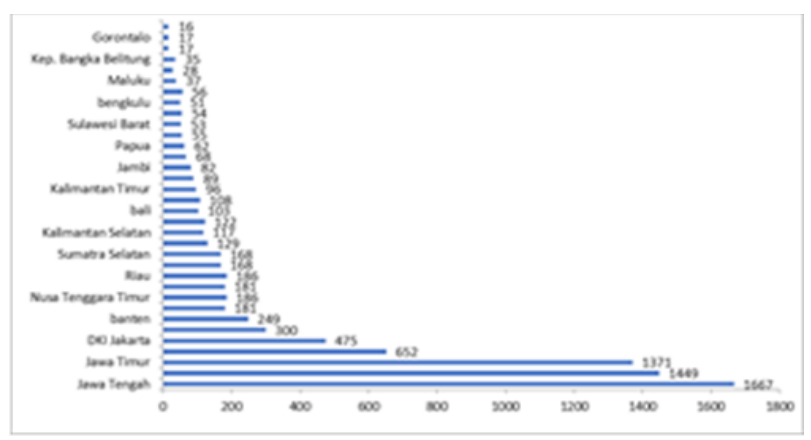

Fig. 5. Report Total Ticket Based on Location (Province)
Based on the results of the graph above, found data that the people of Central Java as the most reporters followed by East Java, DKI Jakarta, and Banten. Reports given to leaders will be reviewed again based on what issues they report, in what month, and can be seen in what districts generally make reports. The local government will implement education policies technically that they and the central government will find a solution for the issue arose.

ULT website has several constraints in its management, such as un-integrated data, which makes it difficult for administrators to answer. The staff who act as the administrators are not from the central unit that holds the data so that questions that are specific or ask the extent of filing of the users take about more one day to answer. Officers from the central unit must serve guests who arrive first at the ULT (face to face). The addition of new features is also needed to adjust the changing times and visitors' needs to the ULT portal.

The official in charge of managing the ULT and the officer who became the administrator explained from their point of view that the website needs vast improvement, but it will be difficult. Constraints on adding features are a matter of time and cost. The re-coding process is not possible because it takes more than six months. If you they want to quick then they must hire a programmer and re-create the website where this will be a question for many people related to work audits. What can be done is to improve the initial application which will later need a factoring process where technical processes are not necessarily understood by the leadership. The refactoring process requires an understanding of the leaders as a key person regarding large expenditures. However, create a new software may not be a right solution because its ability will not be equivalent to the existing system at this time.

They also explained that with the feature update, the application will be bloated, and the database will fall apart, so the possibility is the web must be stopped or under maintenance and cannot receive tickets until the database returns to normal and the code is neatly arranged. This includes optimizing software and hardware. Rearranging software will cause load balancing and database will be needed from the main application. The database on the ULT website needs to be normalized, and the process described requires high cost.

\section{CONCLUSION}

The helpdesk ticketing system is highly recommended to be carried out by other agencies because of the rapid data withdrawal, and the results can be reported to the decisionmaker. On the other hand, rare cases should be handled with care. If creating a new website will incur huge costs, other agencies or companies can use this application for free through a search engine on the internet.

However, management is one of the shortcomings. The helpdesk ticketing system is highly recommended to be carried out by other agencies because of the rapid data withdrawal, and the results can be directly reported to the decision-maker. On the other hand, rare cases should be handled with care. If creating a new website will incur huge costs, other agencies or companies can use this application for free through a search engine on the internet. 
However, management is one of the shortcomings of the ULT website. The need to add new features must be adjusted to the needs of administrators and. Understanding the leaders as a key person and the high costs of web changes are obstacles to the improvement of the current ULT website. Data integration is also needed, therefore administrators can directly answer the user's questions.

Online consultation or live chat is a new feature that has not been optimized because there is a problem with internet signal at the user's location. Another obstacle in the online consultation feature is the lack of administrators who are willing to answer requests for information and complaints in real-time. The appointed officers from each unit who handle online consultation have the main task that sometimes cannot be left. The solution is to recruit new officers that especially in handling online consultation features in real time.

The flow of requests for information and complaints should be improved in connection with the refactoring described above. General questions in both information requests and complaints can be made using Artificial Intelligence or Chatbot. Administrators can directly address messages with specific cases such as bullying or suicide intention from students because human touch is a must for handling cases that are related to a person's psyche.

Online services by adopting the helpdesk ticketing system are highly recommended to be carried out in other agencies seeing the rapid withdrawal of data so that it becomes one of the bases for decision making or evaluation material in making subsequent policies. If creating a new website will incur huge costs, other agencies or companies can use this application for free through a search engine on the internet.

\section{ACKNOWLEDGMENT}

Thanks to Dr. Irwansyah as a mentor in this research. Special thanks to Darmawan Wicaksono as a coordinator and all staff members in the Unit Layanan Terpadu,Ministry of Education and Cultural, for the opportunities and their assistance in collecting data so that this research can be completed.

\section{REFERENCES}

[1] V. J. J. M. Bekkers and V. Homburg, The Information Ecology of Egovernment: E-government as Institutional and Technological Innovation in Public Administration. IOS, 2005.

[2] D. Osimo, "Web 2.0 in Government: Why and How?" Eur. Commisssion Jt. Res. Cent., pp. 1-58, 2008.

[3] R. Heeks, "and Managing eGovernment."

[4] D. Shin and Y. J. Park, "Understanding the Internet of Things ecosystem : multi-level analysis of users, society, and ecology," 2017.

[5] B. Noveriyanto, L. C. Nisa, A. S. Bahtiar, S. Sahri, and I. Irwansyah, "E-GOVERNMENT SEBAGAI LAYANAN KOMUNIKASI PEMERINTAH KOTA SURABAYA (Studi Kematangan egovernment Sebagai Layanan Komunikasi Government to Government, Government to Citizen, Government to Business)," Profetik J. Komun., vol. 11, no. 1, p. 37, 2018.

[6] Z. Fang, "E-Government in Digital Era: Concept, Practice, and Development," Internet Manag., vol. 10, no. 2, pp. 1-22, 2002.

[7] J. L. Bower and C. M. Christensen, "Disruptive technologies: catching the wave," Long Range Plann., 1995.

[8] S. A. Chun, S. Shulman, R. Sandoval, and E. Hovy, "Government 2.0: Making connections between citizens, data and government," Inf. Polity, vol. 15, no. 1,2, pp. 1-9, 2018.

[9] H. K. Aghaei, Sareh and Nematbakhsh, Mohammad Ali and Farsani, "Evolution of the World Wide Web : From Web 1.0 to Web 4.0," Int. J. Web Semant. Technol., vol. 3, no. 1, p. 1, 2012.

[10] B. E. Dixon, "Towards E-Government 2.0," Public Adm. Manag., vol. 15 , pp. $418-454$.

[11] B. S. Noveck, Wiki Government: How Technology Can Make Government Better, Democracy Stronger, and Citizens More Powerful. Brookings Institution Press, 2009.

[12] E. Democracy, Online Town Hall.

[13] E. Bonsón, L. Torres, S. Royo, and F. Flores, "Local e-government 2.0: Social media and corporate transparency in municipalities," Gov. Inf. $Q$., vol. 29, no. 2, pp. 123-132, 2012.

[14] "Fred Beisse - A Guide to Computer User Support for Help Desk and Support Specialists-Course Technology Cengage Learning (2012) (1)."

[15] R. MUDHAR, "Pembangunan Sistem Informasi Helpdesk Ticketing System Menggunakan Django Framework ( Studi Kasus : Smk Saradan ),” pp. 1-100, 2015.

[16] M. Rouse, "Trouble Ticket," 2007. 